Vol. 1 No. 2 September 2021, e-ISSN : 2797-8842 | p-ISSN : 2797-9431

\title{
UPAYA MENINGKATKAN AKTIVITAS DAN HASIL BELAJAR ILMU PENGETAHUAN SOSIAL MELALUI PENGGUNAAN KOOPERATIF LEARNING MODEL JIGSAW PADA SISWA MTS NEGERI MASAMBA KELAS IX A SEMESTER I TAHUN 2014/2015
}

\author{
SUMARDIN \\ MTs Negeri Masamba, Luwu Utara, Sulawesi Selatan \\ Email: sumardinaspa@gmail.com
}

\begin{abstract}
ABSTRAK
Penelitian ini bertujuan agar siswa memiliki aktivitas dan hasil belajar yang tinggi melalui desain pembelajaran yang kooperatif dan kondusif serta partisipatif sehingga mereka akhirnya dapat menguasai materi pelajaran dengan baik. Dengan memberlakukan tindakan di atas, diharapkan aktivitas dan hasil belajar siswa semakin meningkat. Data mengenai efektivitas tindakan dikumpulkan dari observasi kelas, angket skala sikap, wawancara dengan siswa dan refleksi. Pendekatan metode adalah pendekatan kuantitatif dengan metode penelitian eksperimen dan deskriptif. Populasi dalam penelitian ini adalah seluruh siswa kelas IX A MTs Negeri Masamba Tahun Pelajaran 2014/2015 dan yang menjadi subyek dalam penelitian ini adalah siswa kelas IX A MTs Negeri Masamba. pada siklus I jumlah siswa yang tuntas sekitar $84,21 \%$ atau 16 siswa dengan rata-rata 71,81 nilai yang dicapai dan mengalami peningkatan pada siklus ke II dengan jumlah yang tuntas sebanyak 17 siswa atau sebesar 89,47\% dengan rata-rata nilai yang dicapai sebesar 78,23. Dan pada siklus ke III jumlah siswa yang ikut test semuanya dinyatakan tuntas dan terjadi peningkatan jumlah nilai yaitu rata-rata 85,47 \%, dengan tingkat kelulusan $100 \%$. Berdasarkan hasil pengolahan data dan pembahasan hasil penelitian yang telah dilakukan peneliti, maka dapat disimpulkan sebagai berikut: 1 . Dengan menggunakan metode pembelajaran kooperatif tipe jigsaw pada siswa kelas IX A dengan mata pelajaran IPS pada MTs Negeri Masamba sangat berpengaruh terhadap aktivitas belajar siswa..2. Dengan menggunakan metode pembelajaran kooperatif tipe jigsaw pada siswa kelas IX A dengan mata pelajaran IPS pada MTs Negeri Masamba maka mengalami peningkatan hasil belajar siswa,
\end{abstract}

Kata Kunci : Meningkatkan Aktivitas dan Hasil Belajar, Ilmu Pengetahuan Sosial, Model Jigsaw

\section{PENDAHULUAN}

Keberhasilan dalam dunia pendidikan tidak terlepas dari peran guru yang memberikan pelayanan terbaik bagi siswa serta mampu mengemas metode pembelajaran yang dapat diterima sepenuhnya oleh siswa di sekolah. Keberhasilan pengajaran sangat ditentukan manakala pengajaran tersebut mampu mengubah perilaku dan pola pikir peserta didik dalam belajar. Perubahan tersebut dalam arti dapat menumbuh kembangkan potensi-potensi yang dimiliki peserta didik, sehingga peserta didik dapat memperoleh manfaatnya secara langsung dalam perkembangan pribadinya.

Tanggung jawab keberhasilan pengajaran tersebut berada di tangan guru. Artinya, guru harus berupaya semaksimal mungkin untuk mengatur proses pembelajaran sedemikian rupa, sehingga komponen-komponen yang diperlukan dalam pengajaran tersebut dapat berinteraksi antar sesama komponen.

Dalam proses belajar mengajar menurut Sudjarwo, paling tidak ada 6 (enam) kejadian penting yang perlu ada dan perlu diperhatikan, yaitu:

1. Ciptakan dan jaga perhatian siswa.

2. Tunjukkan keterkaitan pesan yang sedang diajarkan dengan pesan yang telah diterima sebelumnya.

3. Arahkan proses belajar mengajar dengan menggunakan bahan-bahan, visual, audio, verbal dan kombinasi dari berbagai bahan tersebut. 
4. Ciptakan komunikasi 2 (dua) arah yang baik dan seimbang, sehingga umpan balik dari dan ke sasaran didik dapat dimanfaatkan untuk mempercepat tingkat kesamaan bahasa dan persepsi peserta didik.

5. Ciptakan dan pelihara kondisi untuk mengingat-ingat, menganalisa, menyimpulkan, menerapkan dan mengevaluasi pesan yang diterima siswa.

6. Selama dan setelah selesai belajar, sebaiknya dilakukan kegiatan evaluasi sesuai dengan tingkat formalitas masing-masing situasi belajar. (Sudjarwo, 2007: 56).

Untuk menciptakan terjadinya 6 (enam) kejadian penting tersebut di atas, antara lain diperlukan penggunaan model pembelajaran yang tepat, agar tercapai kesamaan bahasa dan persepsi yang diterima secara rasional oleh siswa. Untuk mencapai harapan tersebut, seorang guru harus terampil dalam memilih model yang tepat dan sesuai dengan pokok bahasan yang dibahas.

Dalam mengajarkan materi Ilmu Pengetahuan Sosial di kelas, khususnya guru yang mengajar di MTs Negeri Masamba, jarang menggunakan model pembelajaran kebanyakan guru mengajar di kelas masih menggunakan metode ceramah saja (konvensional). Hal ini terjadi karena beberapa alasan berikut:

1. Pengakuan guru, yang menyatakan kurang menguasai metode-metode PBM.

2. Dalam PBM selalu menggunakan metode ceramah dan hapalan yang monoton.

3. Guru mengakui sulitnya menerapkan model pembelajaran yang sesuai dengan karakteristik bahan ajar, khususnya pada pelajaran Ilmu Pengetahuan Sosial.

4. Guru yang telah mengikuti DIKLAT Kurikulum Berbasis Kompetensi masih terbatas.

Dengan adanya masalah-masalah tersebut di atas, maka berdasarkan hasil pengamatan sementara, terlihat dalam proses belajar mengajar di kelas hal-hal sebagai berikut:

1. Rendahnya hasil belajar siswa.

2. Kurang aktivitas siswa dalam mengikuti proses belajar mengajar.

3. Tidak terjadinya pembelajaran yang menyenangkan.

4. Tidak terdapat pembelajaran yang kreatif.

Untuk mengatasi kesulitan proses pembelajaran dalam pelajaran Ilmu Pengetahuan Sosial di atas, maka usaha yang akan ditempuh dalam upaya meningkatkan aktivitas dan hasil belajar siswa adalah dengan penggunaan model pembelajaran sehingga diharapkan akan terjadi Pembelajaran Aktif, Kreatif, Efektif dan Menyenangkan (PAKEM), khususnya pada mata pelajaran Ilmu Pengetahuan Sosial.

Dalam proses belajar mengajar pada pelajaran Ilmu Pengetahuan Sosial, memerlukan model yang tepat agar siswa mampu memahami pesan yang terkandung dalam pelajaran tersebut. Model pembelajaran Jigsaw diharapkan mampu meningkatkan aktivitas dan hasil belajar siswa MTs Negeri Masamba yang akan dilaksanakan melalui Penelitian Tindakan Kelas (PTK) dalam beberapa tahap pembelajaran. Judul dalam penelitian tindakan ini adalah: "Upaya Meningkatkan Aktivitas dan Hasil Belajar Ilmu Pengetahuan Sosial melalui Penggunaan Pembelajaran Kooperatif Learning Model Jigsaw pada Siswa MTs Negeri Masamba Kelas IXA Semester Ganjil pada Mata Pelajaran Ilmu Pengetahuan Sosial.

\section{Model Pembelajaran Kooperatif Tipe Jigsaw}

Jigsaw pertama kali dikembangkan dan diujicobakan oleh Elliot Aronson dan temanteman di Universitas Texas, dan kemudian diadaptasi oleh Slavin dan teman-teman di Universitas John Hopkins. (Arends,1997: 50). Teknik mengajar Jigsaw dikembangkan oleh Aronson et. al. sebagai metode Cooperative Learning. Teknik ini dapat digunakan dalam pengajaran membaca, menulis, mendengarkan ataupun berbicara.

Dalam teknik ini, guru memperhatikan skemata atau latar belakang pengalaman siswa dan membantu siswa mengaktifkan skemata ini agar bahan pelajaran menjadi lebih bermakna. Selain itu, siswa bekerja sama dengan sesama siswa dalam suasana gotong royong dan mempunyai banyak kesempatan untuk mengolah informasi dan meningkatkan keterampilan berkomunikasi. 
Pembelajaran kooperatif tipe Jigsaw adalah suatu tipe pembelajarakooperatif yang terdiri dari beberapa anggota dalam satu kelompok yang bertanggung jawab atas penguasaan bagian materi belajar dan mampu mengajarkan materi tersebut kepada anggota lain dalam kelompoknya. (Arends, 1997: 25).

Model pembelajaran kooperatif tipe Jigsaw merupakan model pembelajaran kooperatif dimana siswa belajar dalam kelompok kecil yang terdiri dari 4-6 orang secara heterogen dan bekerja sama saling ketergantungan yang positif dan bertanggung jawab atas ketuntasan bagian materi pelajaran yang harus dipelajari dan menyampaikan materi tersebut kepada anggota kelompok yang lain. (Arends, 1997: 26).

Jigsaw didesain untuk meningkatkan rasa tanggung jawab siswa terhadap pembelajarannya sendiri dan juga pembelajaran orang lain. Siswa tidak hanya mempelajari materi yang diberikan, tetapi mereka juga harus siap memberikan dan mengajarkan materi tersebut satu dengan yang lain dan harus bekerja sama secara kooperatif untuk mempelajari materi yang ditugaskan. (Lie A., 2004: 35).

Para anggota dari tim-tim yang berbeda dengan topik yang sama bertemu untuk diskusi (tim ahli) saling membantu satu sama lain tentang topik pembelajaran yang ditugaskan kepada mereka. Kemudian siswa-siswa itu kembali kepada tim/kelompok asal untuk menjelaskan kepada anggota kelompok yang lain tentang apa yang telah mereka pelajari sebelumya pada pertemuan tim ahli.

Pada model pembelajaran kooperatif tipe Jigsaw, terdapat kelompok asal dan kelompok ahli. Kelompok asal yaitu kelompok induk siswa yang beranggotakan siswa dengan kemampuan, asal dan latar belakang keluarga yang beragam. Kelompok asal merupakan gabungan dari beberapa ahli. Kelompok ahli yaitu kelompok siswa yang terdiri dari anggota kelompok asal yang berbeda yang ditugaskan untuk mempelajari dan mendalami topik tertentu dan menyelesaikan tugas-tugas yang berhubungan dengan topiknya untuk kemudian dijelaskan kepada anggota kelompok asal.

\section{Pembelajaran Konvensional}

Pembelajaran konvensional adalah model pembelajaran biasa digunakan oleh guru selama ini. Pembelajaran konvensional menurut Wahidin (2006: 32) adalah suatu pembelajaran yang menekankan kepada proses penyampaian materi secara verbal atau ceramah dari guru kepada kelompok siswa dengan maksud agar siswa dapat menguasai materi pelajaran secara optimal. Dalam pembelajaran ini guru lebih dominan daripada siswa.

\section{Hakikat Aktivitas Belajar dalam Pembelajaran Ilmu Pengetahuan Sosial}

Aktivitas belajar siswa dalah keterlibatan siswa dalam bentuk sikap, pikiran, perhatian dan aktivitas dalam kegiatan pembalajran guna menunjang keberhasilan proses belajar mengajar dan memperoleh manfaat dari kegiatan tersebut. Peningkatan aktivitas belajar siswa, yaitu meningkatnya jumlah siswa yang terlibat aktif belajar, meningkatnya jumlah siswa yang bertanya dan menjawab, meningkatnya jumlah yang berinteraksi membahas materi pelajaran.

Metode mengajar yang bersifat partisipatoris yang dilakukan guru akan mampu membawa siswa dalam situasi yang lebih kondusif, karena siswa lebih berperan dan lebih terbuka serta sensitf dalam kegiatan pembelajaran.

\section{Analisis Penyebab}

Dari permasalahan yang diteliti untuk meningkatkan aktivitas belajar siswa dewasa ini adalah kecenderungan siswa hanya terbiasa menggunakan sebagian kecil saja dari potensi atau kemampuan berpikirnya. Begitu pula dengan penggunaan metode pembelajaran yang monoton atau tidak variatif, maka dengan menggunakan metode pembelajaran kooperatif tipe Jigsaw, siswa akan lebih mudah menemukan dan memahami konsep yang sulit jika mereka berdiskusi dan bekerja sama dalam kelompok belajarnya. Siswa juga akan lebih aktif dalam belajar yang akhirnya proses pembelajaran berjalan dengan kondusif. Berdasarkan penelitian tersebut, maka peneliti berasumsi bahwa metode kooperatif tipe Jigsaw dapat meningkatkan aktivitas belajar 
siswa MTSN Masamba dalam mata pelajaran Ilmu Pengetahuan Sosial khususnya pada kompetensi dasar memahami dan mempraktikkan tentang uang dan lembaga keuangan.

\section{METODE PENELITIAN}

Pendekatan metode penelitian yang digunakan dalam penelitian tindakan kelas ini adalah pendekatan kuantitatif dengan metode penelitian eksperimen dan deskriptif. Metode penelitian eksperimen digunakan untuk menjawab pertanyaan penelitian motivasi siswa dan metode penelitian kualitatif digunakan untuk menjawab pertanyaan tentang sikap siswa terhadap penerapan metode pembelajaran kooperatif tipe Jigsaw. (Sukmadinata, 2006).

Penelitian ini disusun untuk memecahkan suatu masalah serta melakukan perubahan yang berfungsi sebagai peningkatan upaya perbaikan dan dilakukan dengan melaksanakan tindakan untuk mencari jawaban atas permasalahan yang diangkat dari kegiatan sehari-hari di kelas.

\section{HASIL DAN PEMBAHASAN}

Pembelajaran Ilmu Pengetahuan Sosial di kelas IX A MTs Negeri Masamba dilakukan tiga siklus. Pada setiap siklus data yang diambil adalah berupa pertanyaan dalam bentuk soal pada akhir siklus. Hasil observasi siswa dari siklus dapat dilihat pada tabel-tabel berikut:

Tabel 1. Daftar Hasil Test Siswa Siklus I Pada Siswa Kelas IXA MTS Negeri Masamba Mata Pelajaran IPS KKM 70 Tahun Pelajaran 2014/2015

\begin{tabular}{|c|c|c|c|c|}
\hline $\begin{array}{l}\text { NOM } \\
\text { OR }\end{array}$ & NAMA SISWA & $\begin{array}{l}\text { L/ } \\
\mathbf{P}\end{array}$ & NILAI & KETERANGAN \\
\hline 1 & Andi Kaso & $\mathrm{P}$ & 65 & Tidak Tuntas \\
\hline 2 & Adibah Aliyah Naila & $\mathrm{L}$ & 70 & Tuntas \\
\hline 3 & Ahmad Rifyal & $\mathrm{L}$ & 70 & Tuntas \\
\hline 4 & Anggita & $\mathrm{P}$ & 72 & Tuntas \\
\hline 5 & Anjani & $\mathrm{L}$ & 74 & Tuntas \\
\hline 6 & Arifah & $\mathrm{P}$ & 78 & Tuntas \\
\hline 7 & A. Irham & $\mathrm{L}$ & 80 & Tuntas \\
\hline 8 & Dini & $\mathrm{P}$ & 81 & Tuntas \\
\hline 9 & Haidir & $\mathrm{L}$ & 80 & Tuntas \\
\hline 10 & Herawati & $\mathrm{P}$ & 80 & Tuntas \\
\hline 11 & Lukman & $\mathrm{L}$ & 75 & Tuntas \\
\hline 12 & Lutfiah Kalsum & $\mathrm{P}$ & 70 & Tuntas \\
\hline 13 & Marwa & $\mathrm{P}$ & 71 & Tuntas \\
\hline 14 & Muh. Yusuf & $\mathrm{P}$ & 70 & Tuntas \\
\hline 15 & Nur Hikma & $\mathrm{P}$ & 65 & Tidak Tuntas \\
\hline 16 & Rahmat Al-Amin & $\mathrm{L}$ & 70 & Tuntas \\
\hline 17 & Ririn Saputri & $\mathrm{P}$ & 72 & Tuntas \\
\hline 18 & Fauziah Azzhhra & $\mathrm{P}$ & 70 & Tuntas \\
\hline 19 & Muh.Ridzqullah & $\mathrm{P}$ & 60 & Tidak Tuntas \\
\hline
\end{tabular}




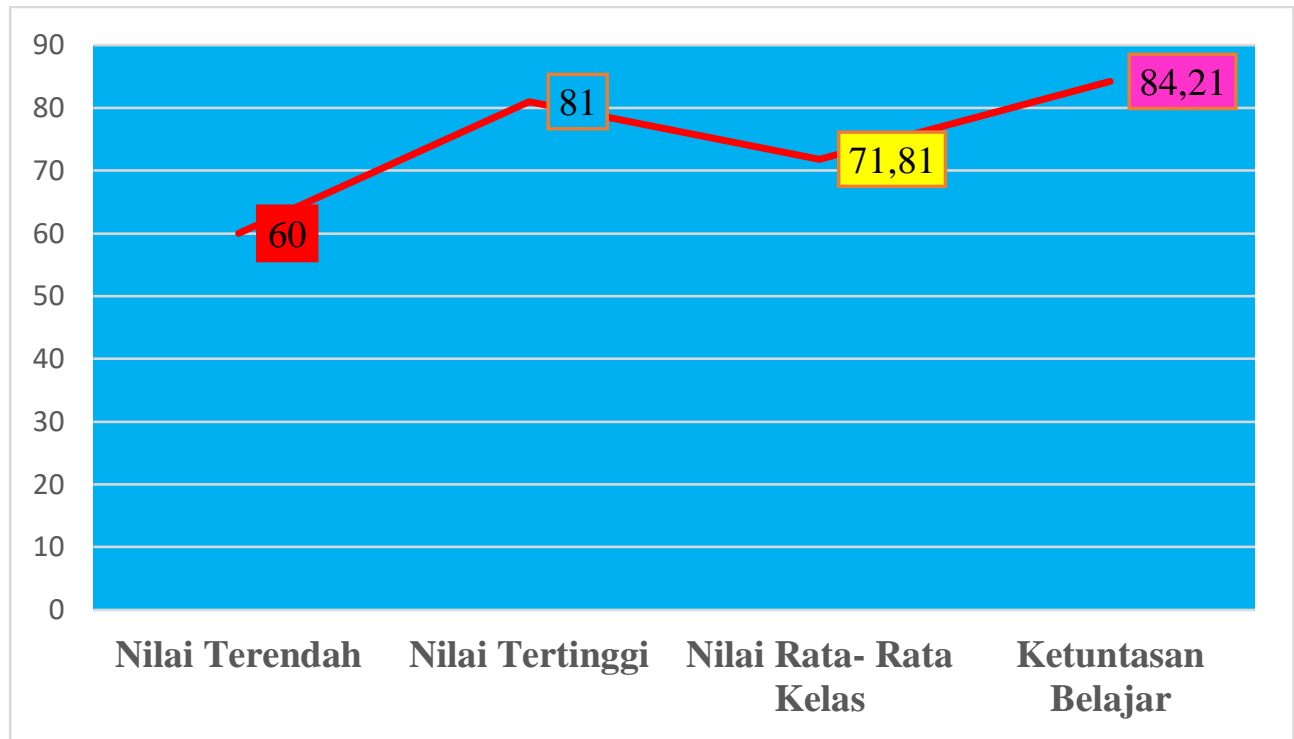

Gambar 1. Grafik Perkembangan Nilai Hasil Belajar Siswa pada Siklus 1

Apakah penggunaan pembelajaran kooperatif learning model jiqsaw dapat meningkatkan aktivitas dan hasil belajar siswa dapat dilihat dari siklus I setelah mendapat perlakuan pembelajaran kooperatif learning model jiqsaw terdapat jumlah siswa yang mengikuti test dengan materi uang dan lembaga keuangan lainnya pada mata pelajaran IPS nilai terendah 60 sedangkan nilai tertinggi 81, yang tidak tuntas sebanyak 3 siswa atau 15,79\% dengan rata-rata nilai yang didapatkan 63,33. Sedangkan siswa yang tuntas sebanyak 16 siswa atau $84,21 \%$ dan rata-rata nilai yang dicapai sebesar 71,81 . Dari data tersebut sebenarnya sudah mencapai kemajuan dari sisi aktivitas dan hasil belajar siswa.Namun nilai yang dicapai rata rata kelas baru $71,81 \%$.

Hasil yang belum memuaskan pada siklus I antara lain dikarenakan : siswa pada kelompok staf ahli masih merasa belum beradaftasi sesama staf ahli, terutama dalam penguasaan keterampilan berbicara, menbaca maupun menulis, ketika kembali kekolompok asal masih ada siswa bila dijelaskan masih menpunyai pemahaman teori yang berbeda. Disamping itu siswa yang bertindak sebagai staf ahli ketika berada dikelompoknya masih belum percaya diri yang cukup dalam menjelaskan teori kepada temannya sehingga ada kebuntuan dalam diskusi

Tabel 2. Daftar Hasil Test Siswa Siklus II Pada Siswa Kelas IXA MTS Negeri Masamba Mata Pelajaran IPS KKM 70, Tahun Pelajaran 2014/2015

\begin{tabular}{|c|l|c|c|l|}
\hline $\begin{array}{c}\text { NOM } \\
\text { OR }\end{array}$ & \multicolumn{1}{|c|}{ NAMA SISWA } & $\begin{array}{c}\text { L/ } \\
\text { P }\end{array}$ & NILAI & \multicolumn{1}{|c|}{$\begin{array}{c}\text { KETERANGA } \\
\text { Naso }\end{array}$} \\
\hline 1 & Andi Kaso & P & 67 & Tidak Tuntas \\
\hline 2 & Adibah Aliyah Naila & L & 73 & Tuntas \\
\hline 3 & Ahmad Rifyal & L & 75 & Tuntas \\
\hline 4 & Anggita & P & 75 & Tuntas \\
\hline 5 & Anjani & L & 76 & Tuntas \\
\hline 6 & Arifah & P & 80 & Tuntas \\
\hline 7 & B.Irham & L & 81 & Tuntas \\
\hline 8 & Dini & P & 84 & Tuntas \\
\hline 9 & Haidir & L & 85 & Tuntas \\
\hline 10 & Herawati & P & 85 & Tuntas \\
\hline 11 & Lukman & L & 80 & Tuntas \\
\hline 12 & Lutfiah Kalsum & P & 78 & Tuntas \\
\hline 13 & Marwa & P & 78 & Tuntas \\
\hline
\end{tabular}


Vol. 1 No. 2 September 2021, e-ISSN : 2797-8842 | p-ISSN : 2797-9431

\begin{tabular}{|c|l|c|c|l|}
\hline 14 & Muh. Yusuf & P & 76 & Tuntas \\
\hline 15 & Nur Hikma & P & 78 & Tuntas \\
\hline 16 & Rahmat Al-Amin & L & 76 & Tuntas \\
\hline 17 & Ririn Saputri & P & 72 & Tuntas \\
\hline 18 & Fauziah Azzhhra & P & 78 & Tuntas \\
\hline 19 & Muh.Ridzqullah & P & 69 & Tidak Tuntas \\
\hline
\end{tabular}

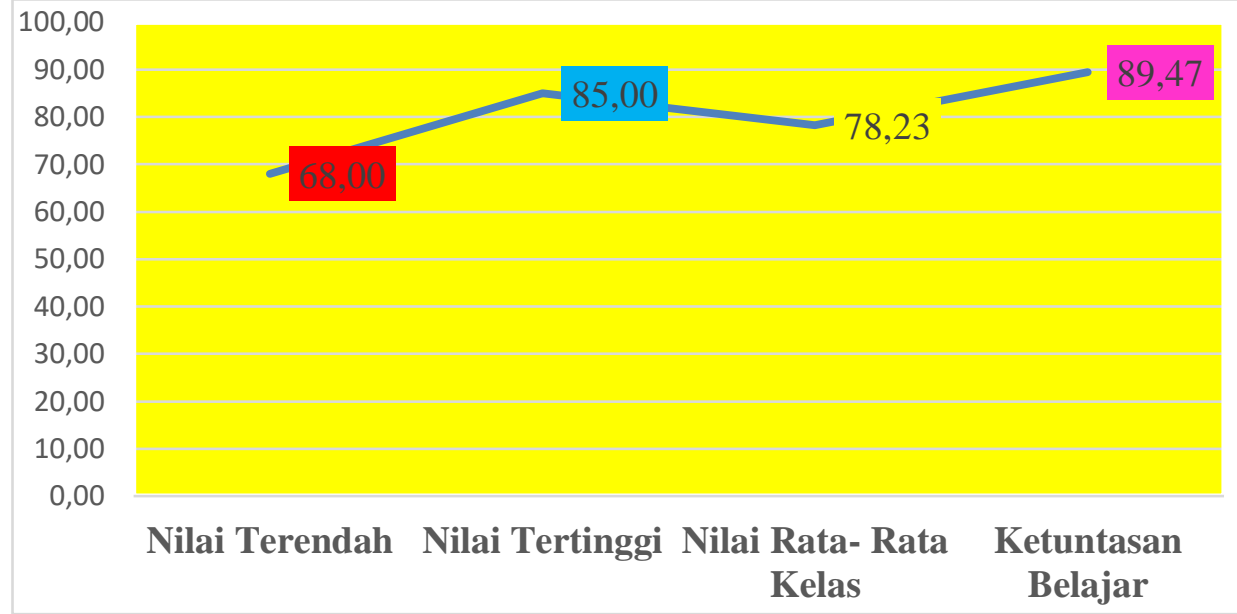

Gambar 2 Grafik Perkembangan Nilai Hasil Belajar Siswa pada Siklus II

Berdasarkan data diatas pada siklus II terdapat jumlah siswa yang mengikuti test dengan materi uang dan lembaga keuangan lainnya dengan menggunakan metode kooperatif model jigsaw pada mata pelajaran IPS nilai terendah 68, nilai tertinggi 85 , yang tidak tuntas sebanyak 2 siswa atau 10,53 \% dengan rata-rata nilai yang didapatkan sebesar 68,00. Sedangkan siswa yang tuntas sebanyak 17 siswa atau $89,47 \%$ dengan rata-rata nilai yang dicapai sebesar 78,23. Berdasarkan pada siklus I jika dibandingkan dengan siklus II maka terjadi peningkatan jumlah siswa yang tuntas, serta peningkatan nilai yang didapatkan siswa tersebut.

Peningkatan nilai yang didapat oleh siswa disebabkan penerapan model pembelajaran learning model jiqsaw sudah mulai dipahami oleh siswa. Siswa pada siklus I belum percaya diri, menpunyai pemahaman yang berbeda, kemanpuan keterampilan berbicara, menulis dan menbaca yang masih perlu dilatih, namun pada siklus ke II sudah agak bagus khususnya penguasaan materi dalam menyampaikan kepada masing-masing kelompok asal. Disamping itu Bapak guru senantiasa menberikan bimbingannya.

Tabel 3. Daftar Hasil Test Siswa Siklus III Pada Siswa Kelas IXA MTS Negeri Masamba Mata Pelajaran IPS KKM 70 Tahun Pelajaran 2014/2015

\begin{tabular}{|c|l|c|c|l|}
\hline $\begin{array}{c}\text { NO } \\
\text { MO } \\
\text { R }\end{array}$ & NAMA SISWA & $\begin{array}{c}\text { L/ } \\
\text { P }\end{array}$ & NLAI & KETERANGAN \\
\hline 1 & Andi Kaso & P & 75 & Tuntas \\
\hline 2 & Adibah Aliyah Naila & L & 80 & Tuntas \\
\hline 3 & Ahmad Rifyal & L & 80 & Tuntas \\
\hline 4 & Anggita & P & 80 & Tuntas \\
\hline 5 & Anjani & L & 81 & Tuntas \\
\hline 6 & Arifah & P & 90 & Tuntas \\
\hline 7 & C. Irham & L & 91 & Tuntas \\
\hline 8 & Dini & P & 90 & Tuntas \\
\hline 9 & Haidir & L & 95 & Tuntas \\
\hline
\end{tabular}


Vol. 1 No. 2 September 2021, e-ISSN : 2797-8842 | p-ISSN : 2797-9431

\begin{tabular}{|l|l|c|c|l|}
\hline 10 & Herawati & P & 94 & Tuntas \\
\hline 11 & Lukman & L & 90 & Tuntas \\
\hline 12 & Lutfiah Kalsum & P & 85 & Tuntas \\
\hline 13 & Marwa & P & 86 & Tuntas \\
\hline 14 & Muh. Yusuf & P & 85 & Tuntas \\
\hline 15 & Nur Hikma & P & 87 & Tuntas \\
\hline 16 & Rahmat Al-Amin & L & 84 & Tuntas \\
\hline 17 & Ririn Saputri & P & 87 & Tuntas \\
\hline 18 & Fauziah Azzhhra & P & 88 & Tuntas \\
\hline 19 & Muh.Ridzqullah & P & 76 & Tuntas \\
\hline
\end{tabular}

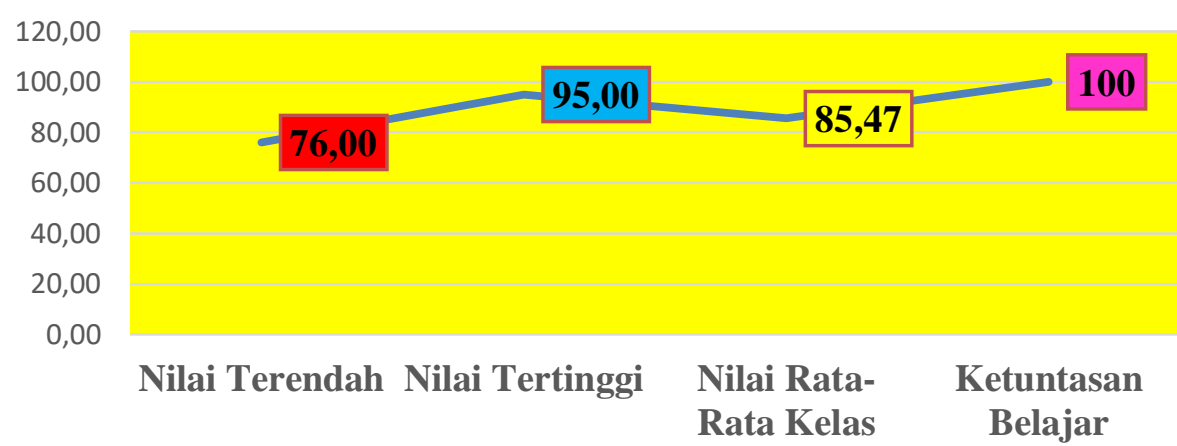

\section{Gambar 3. Grafik Perkembangan Nilai Hasil Belajar Siswa pada Siklus III}

Berdasarkan data diatas pada siklus III terdapat jumlah siswa yang mengikuti test dengan materi uang dan lembaga keuangan lainnya dengan menggunakan metode kooperatif model jigsaw pada mata pelajaran IPS sebanyak 19 siswa yang mengikuti test semuanya dinyatakan tuntas atau tingkat ketuntasannya $100 \%$ nilai terendah 76 dan nilai tertinggi 95 , dengan nilai rata-rata yang dicapai sebesar 85,47.

Pada siklus I, II, masih ada siswa yang tidak tuntas. Namun dengan penerapan pembelajaran learning model jiqsaw pada siklus III jumlah siswa semuanya tuntas. Hal ini menandakan bahwa siswa sudah mampu menjalankan segala bimbingan oleh bapak guru sesuai pembelajaran learning model jiqsaw.Siswa sudah sangat percaya diri tanpa harus malu, lebih bertanggung jawab,bersemangat, rajin bertanya sehingga segala kekurangan yang ada pada siklus I maupun II dapat lebih diperjelas atau dipahami pada siklus III.

Tabel 4. Daftar Rekapitulasi Siswa Kelas IXA MTs Negeri Masamba Mata Pelajaran IPS KKM 70 Pada siklus I,II,dan III Tabel IV

\begin{tabular}{|c|l|c|c|c|c|c|c|}
\hline \multirow{2}{*}{ NO } & \multirow{2}{*}{ NAMA } & \multicolumn{6}{|c|}{ SIKLUS } \\
\cline { 3 - 8 } & & I & Ket & II & Ket & III & Ket \\
\hline 1 & $\begin{array}{l}\text { Alfania Laela } \\
\text { Azzahra }\end{array}$ & 65 & $\mathrm{TT}$ & 67 & $\mathrm{TT}$ & 75 & $\mathrm{~T}$ \\
\hline 2 & Alfin & 70 & $\mathrm{~T}$ & 73 & $\mathrm{~T}$ & 80 & $\mathrm{~T}$ \\
\hline 3 & Andi Akbar & 70 & $\mathrm{~T}$ & 75 & $\mathrm{~T}$ & 80 & $\mathrm{~T}$ \\
\hline 4 & Asniati & 72 & $\mathrm{~T}$ & 75 & $\mathrm{~T}$ & 80 & $\mathrm{~T}$ \\
\hline 5 & Fasli Fahrezi & 74 & $\mathrm{~T}$ & 76 & $\mathrm{~T}$ & 81 & $\mathrm{~T}$ \\
\hline 6 & Gebrila & 78 & $\mathrm{~T}$ & 80 & $\mathrm{~T}$ & 90 & $\mathrm{~T}$ \\
\hline 7 & Indra Sigit & 80 & $\mathrm{~T}$ & 81 & $\mathrm{~T}$ & 91 & $\mathrm{~T}$ \\
\hline 8 & Khumairah & 81 & $\mathrm{~T}$ & 84 & $\mathrm{~T}$ & 90 & $\mathrm{~T}$ \\
\hline 9 & Laode Darfin Idhar & 80 & $\mathrm{~T}$ & 85 & $\mathrm{~T}$ & 95 & $\mathrm{~T}$ \\
\hline 10 & Lia & 80 & $\mathrm{~T}$ & 85 & $\mathrm{~T}$ & 94 & $\mathrm{~T}$ \\
\hline 11 & Muh. Haikal Alfarisi & 75 & $\mathrm{~T}$ & 80 & $\mathrm{~T}$ & 90 & $\mathrm{~T}$ \\
\hline 12 & Nilam Cahya Ningsih & 70 & $\mathrm{~T}$ & 78 & $\mathrm{~T}$ & 85 & $\mathrm{~T}$ \\
\hline
\end{tabular}


Vol. 1 No. 2 September 2021, e-ISSN : 2797-8842 | p-ISSN : 2797-9431

\begin{tabular}{|c|l|c|c|c|c|c|c|}
13 & Nirma Yunita & 71 & $\mathrm{~T}$ & 78 & $\mathrm{~T}$ & 86 & $\mathrm{~T}$ \\
\hline 14 & Nurul Hafidza & 70 & $\mathrm{~T}$ & 76 & $\mathrm{~T}$ & 85 & $\mathrm{~T}$ \\
\hline 15 & $\begin{array}{l}\text { Nurul Zhalzabila } \\
\text { Syam }\end{array}$ & 65 & $\mathrm{TT}$ & 78 & $\mathrm{~T}$ & 87 & $\mathrm{~T}$ \\
\hline 16 & Rakhlin & 70 & $\mathrm{~T}$ & 76 & $\mathrm{~T}$ & 84 & $\mathrm{~T}$ \\
\hline 17 & Sucianti & 72 & $\mathrm{~T}$ & 72 & $\mathrm{~T}$ & 87 & $\mathrm{~T}$ \\
\hline 18 & Tarisa .B & 70 & $\mathrm{~T}$ & 78 & $\mathrm{~T}$ & 88 & $\mathrm{~T}$ \\
\hline 19 & Tendri & 60 & $\mathrm{TT}$ & $\begin{array}{c}69 \\
146\end{array}$ & $\mathrm{TT}$ & $\begin{array}{c}76 \\
162 \\
6\end{array}$ & $\mathrm{~T}$ \\
& JUMLAH & 1373 & & $\begin{array}{c}16 \\
6\end{array}$ & & &
\end{tabular}

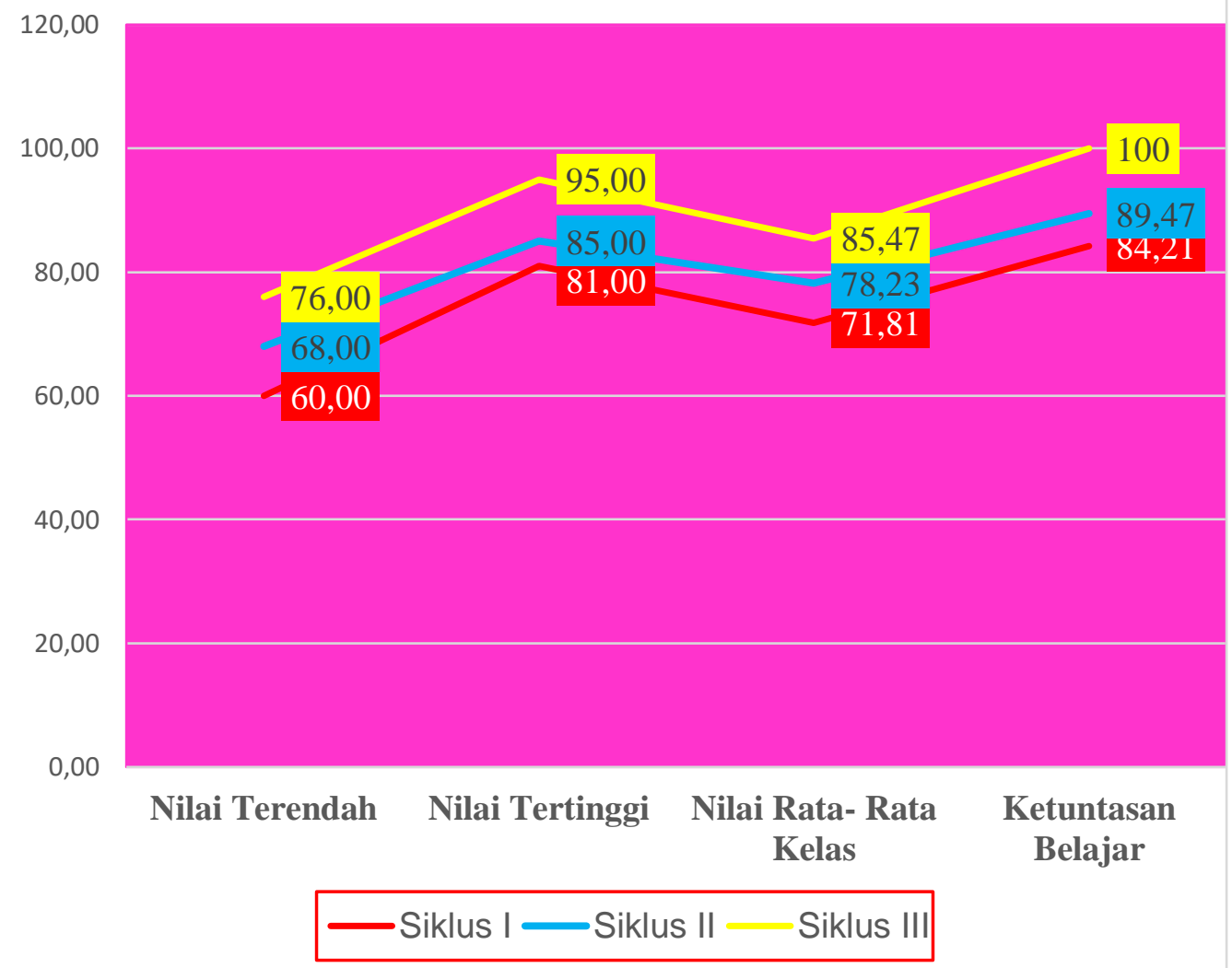

\section{Gambar 4. Grafik Rekapitulasi Peningkatan Nilai Hasil Belajar Siswa dari Siklus I, II dan III}

Pada siklus I jumlah siswa yang tuntas sekitar $84,21 \%$ atau 16 siswa dengan rata-rata 71,81 nilai yang dicapai dan mengalami peningkatan pada siklus ke II dengan jumlah yang tuntas sebanyak 17 siswa atau sebesar 89,47\% dengan rata-rata nilai yang dicapai sebesar 78,23. Dan pada siklus ke III jumlah siswa yang ikut test semuanya dinyatakan tuntas dan terjadi peningkatan jumlah nilai yaitu rata-rata 85,47 , dengan tingkat kelulusan $100 \%$. Jadi secara keseluruhan baik dari siklus I, II maupun III terlihat peningkatan aktivitas dan hasil belajar siswa yang signifikan.Hal ini dapat terjadi berkat partisipasi siswa yang cukup tinggi, karena Pembelajaran model jiqsaw didesain lebih menyenangkan mudah dipahami oleh siswa dan lebih kreatif, tidak monoton guna menghindari timbulnya kejenuhan siswa didalam mengikuti pelajaran IPS.

Siklus pertama dapat dilakukan dalam dua kali pertemuan, yakni siswa dibagi menjadi empat kelompok dengan masing-masing kelompok beranggotakan lima orang, dengan 
pembentukan kelompok berdasarkan pada heterogenitas, keaktifan dengan menggunkan teknik penyeleksian. Untuk memberikan suasana yang menyenangkan dalam awal diskusi, siswa diajak untuk melihat film yang berhubungan dengan uang dan lembaga keuangan. Melalui pemutaran film ini siswa dapat terbuka pikiran dan imajinasinya untuk mempersiapkan pembelajaran materi uang dan lembaga keuangan pada mata pelajaran Ilmu Pengetahuan Sosial.

Adapun langkah-langkah pembelajaran kooperatif tipe Jigsaw dapat dilihat pada urutan sebagai berikut:

Pendahuluan : Mempersiapkan konsep materi yang akan dijadikan bahan pembelajaran

KD : Menjelaskan pengertian dan pentingnya uang dan lembaga keuangan

Indikator:

1. Menjelaskan pengertian dan pentingnya uang dan lembaga keuangan,

2. Mempraktikkan uang dan lembaga keuangan,

Langkah utama:

a. Guru membagi siswa kepada lima kelompok

b. Guru menjelaskan tujuan pembelajaran yaitu menyebutkan uang dan lembaga keuangan.

c. Guru menjelaskan tugas-tugas dan membentuk kelompok diskusi sesuai dengan karakteristik kooperatif tipe Jigsaw.

d. Siswa ditugaskan untuk berdiskusi dengan kelompoknya masing-masing.

e. Di antara kelompok tersebut berkumpul para kelompok ahli untuk membahas materi yang sama.

f. Perwakilan dari setiap kelompok ahli tersebut mempresentasikan hasil diskusinya.

g. Seluruh kelompok menanggapi hasil pembahasan dalam diskusi kelompok ahli.

h. Guru memberikan teknik pemberian skor individu dan kelompok agar siswa termotivasi untuk aktif dalam belajar.

i. Guru memberikan penguatan materi/penjelasan atas materi yang sedang dibahas.

j. Guru memberikan kuis untuk membantu hasil belajar siswa.

k. Guru mengulas kembali materi yang telah dibahas.

1. Tutup

m. Guru memberikan penilaian kepada kelompok siswa yang melakukan penelaahan pada diskusi tersebut.

Hasil pengamatan selama proses pembelajaran dan isian angket yang diisi oleh setiap siswa terlihat peserta didik selalu termotivasi untuk mengikuti pelajaran dengan metode pembelajaran kooperatif tipe Jigsaw. Model kooperatif tipe Jigsaw ini merupakan metode yang sangat sesuai untuk diterapkan dalam pembelajaran Ilmu Pengetahuan Sosial. Sebab jika dilihat dari persentase ketercapaian pada setiap siklus mengalami kenaikan yang sangat signifikan. Untuk itu sesuai dengan kajian teoritik/pustaka pada bab dua (II) tentang aktivitas belajar dapat diuji kebenarannya pada hipotesis yang telah ditentukan. Dengan metode kooperatif tipe Jigsaw dapat menimbulkan aktivitas belajar siswa dalam pembelajaran Ilmu Pengetahuan Sosial di kelas IXA pada MTs Negeri Masamba.

Metode kooperatif tipe Jigsaw ini sangat efektif digunakan untuk pembelajaran Ilmu Pengetahuan Sosial, sebab hal ini dapat dilihat dari persentase kenaikan masing-masing siklus. Kemudian, pola yang harus digunakan guru dalam melakukan pembelajaran harus lebih menyenangkan agar pikiran, perasaan siswa dapat berkonsentrasi untuk melakukan pembelajaran.

\section{KESIMPULAN}


Berdasarkan hasil pengolahan data dan pembahasan hasil penelitian yang telah dilakukan peneliti, maka dapat disimpulkan sebagai berikut: 1. Dengan menggunakan metode pembelajaran kooperatif tipe jigsaw pada siswa kelas IXA dengan mata pelajaran IPS pada MTs Negeri Masamba sangat berpengaruh terhadap aktivitas belajar siswa didalam kelas. 2. Dengan menggunakan metode pembelajaran kooperatif tipe jigsaw pada siswa kelas IXA dengan mata pelajaran IPS pada MTs Negeri Masamba maka mengalami peningkatan hasil belajar siswa, pada siklus I jumlah siswa yang tuntas sekitar $84,21 \%$ atau 16 siswa dengan rata-rata 71,81 nilai yang dicapai dan mengalami peningkatan pada siklus ke II dengan jumlah yang tuntas sebanyak 17 siswa atau sebesar 89,47\% dengan rata-rata nilai yang dicapai sebesar 78,23. Dan pada siklus ke III jumlah siswa yang ikut test semuanya dinyatakan tuntas dan terjadi peningkatan jumlah nilai yaitu rata-rata 85,47, dengan tingkat kelulusan $100 \%$. Jadi model Pembelajaraan kooperatif tipe jigsaw dapat meningkatkan hasil belajar siswa.

\section{DAFTAR PUSTAKA}

Arikunto, Suharsimi. dkk. (2008). Penelitian Tindakan Kelas. Jakarta: Bumi Aksara.

Chalid Narbuko. Abu Ahmadi. (2012). Metodologi Penelitian Pendidikan.Jakarta. Bumi Aksara

Depag RI. (2002). Standar Kompetensi Madrasah Tsanawiyah. Jakarta: Departemen Agama.

Djamarah, Syaiful Bahri. (2002). Strategi Belajar Mengajar. Jakarta: Rineka Cipta.

Hamzah B. Umo. (2012). Model Pembelajaran. Jakarta: Bumi Aksara.

Jumanta Hamdayama. (2016). Metodologi Pengajaran.Jakarta: Bumi Aksara.

Lie A. (2004). Cooperative Leaning. Jakarta:Gramedia Widiasarana Indonesia.

M.Djunaidi, Fauzan Almanshur. (2012). Metodologi Penelitian Kualitatif: Yogyakarta: AM

Media

Oemar Hamalik. (2011). Perencanaan Pengajaran. Jakarta: Bumi Aksara.

Rustiyah, N.K. (199)1. Strategi Belajar Mengajar. Jakarta: Bina Aksara.

Sudjarwo, dkk. (2007). Proses Pengajaran. Yogyakarta: Pustaka Pelajar.

Sugiyono. (2006). Metode Penelitian Bisnis. Jakarta: Salemba Empat.

Sukmadinata, Nana Syaodih. (2006). Metode Penelitian Pendidikan Bandung: Remaja

Rosda Karya.

Sutikno, M. Sobary, (2007). Belajar dan Pembelajaran. Bandung: Prospect.

Wahidin. (2006). Pembelajaran Konvensional. Surabaya: Usaha Nasional. 